\title{
Estudo de barras de aço comprimidas do sistema light steel framing com a presença de furos
}

\author{
Rafael Luiz Galvão de Oliveira ${ }^{1 *}$, Rodrigo Barreto Caldas ${ }^{2}$ e Francisco Carlos \\ Rodrigues $^{3}$ \\ ${ }^{1}$ Engenheiro Civil, rafaelluiz_go@hotmail.com \\ ${ }^{2}$ Departamento de Engenharia de Estruturas, Universidade Federal de Minas \\ Gerais, caldas@dees.ufmg.br \\ ${ }^{3}$ Departamento de Engenharia de Estruturas, Universidade Federal de Minas \\ Gerais, francisco@dees.ufmg.br
}

\section{Study of steel bars of the light steel framing system under compression with the presence of holes}

\begin{abstract}
Resumo
Neste trabalho é apresentado um estudo sobre a capacidade resistente de perfis formados a frio, comprimidos, com a presença de furos. A ABNT NBR 14762:2010 somente aborda o dimensionamento em tal situação para barras tracionadas e para ligações parafusadas. São apresentados estudos realizados e o procedimento da norma norte americana AISI S100-16 para o dimensionamento de perfis com furos. Foi desenvolvido um software para dimensionamento de perfis formados a frio com e sem a presença de furos. A presença de furos em almas de perfis Ue pode causar redução de até $23 \%$ na capacidade resistente de barras em compressão, portanto deve ser considerada no dimensionamento. Tal redução ocorre em função da modificação na condição de contorno da alma do perfil. São apresentadas as reduções percentuais da força resistente para os perfis usuais do LSF.
\end{abstract}

Palavras-chave: perfis de aço formados a frio, light steel framing, furos, perfurações

\begin{abstract}
The aim of this study is to present a theoretical study on the resistance capacity of cold-formed steel columns with holes. The Brazilian Standard ABNT NBR 14762:2010 presents the design rules only for tensile frames and bolted connections. It was presented some studies on the cold-formed steel profiles with holes and was presented a design method for cold-formed sections with holes of North American Standard AISI S100-16. It was developed a software for the design of cold-formed sections with or without openings. It was founded that the presence of the holes in web can cause a reduction in the resistance capacity of columns up to $23 \%$, therefore the presence of holes should be taken in accounting on the structural design. That reduction is due to the change of boundary condition of the web of a column. It was presented that the reduction factors of the usual profiles on LSF system.
\end{abstract}

Keywords: cold-formed steel profiles, light steel framing, holes, perforations

* Autor correspondente 


\section{Introdução}

O sistema construtivo Light Steel Framing (LSF) tem seu uso crescente em edificações residenciais no Brasil. Ele é composto por subsistemas estruturais trabalhando de forma conjunta, com uma concepção racional para fabricação, transporte e montagem. Os montantes são compostos por perfis $U$ enrijecidos (Ue) equidistantes de $400 \mathrm{~mm}$ ou $600 \mathrm{~mm}$.

Os perfis formados a frio (PFF) adotados na constituição do reticulado metálico do sistema LSF usualmente recebem furos para a passagem e acomodação de tubulações elétricas, hidráulicas, de gás, entre outros. A presença de furos em perfis é comum, inclusive para conexões com elementos construtivos e estruturais.

Tais furos usualmente são feitos na alma dos perfis por punção ou com a utilização de brocas, e podem alterar a rigidez e a capacidade resistente das barras (Moen e Schafer, 2008). Quando furos são feitos na alma de perfis formados a frio, a rigidez rotacional fornecida pela alma à mesa é reduzida, de modo que força axial de flambagem distorcional elástica e momento fletor de flambagem distorcional elástica diminuem (Moen e Schafer, 2009).

Apesar das alterações citadas anteriormente, a norma de "Dimensionamento de Estruturas de Aço Constituídas por Perfis Formados a Frio", ABNT NBR 14762:2010, só contempla em seu escopo a ocorrência de furos no capítulo de barras submetidas à força axial de tração e de ligações parafusadas. O código normativo norte americano American Iron and Steel Institute (AISI) S100-16, apresenta recomendações e fórmulas que levam em conta a presença de furos circulares e não circulares nos perfis. Parte da formulação presente na AISI S100-16 foi baseada nos estudos citados a seguir.

Para avaliar o comportamento de barras comprimidas com seção Ue e furos oblongos na alma, os autores (Moen e Schafer, 2008) realizaram ensaios destrutivos com 24 corpos de prova. Os perfis curtos $(610 \mathrm{~mm}$ ) receberam um furo oblongo, enquanto os perfis de comprimento intermediário $(1219 \mathrm{~mm})$ receberam dois furos oblongos, sendo estes localizados na região onde se esperava o máximo deslocamento devido à instabilidade. 
Moen e Schafer (2008) concluíram que a presença de furos oblongos discretos na alma de perfis Ue sujeitos à força axial de compressão provoca uma redução na força axial de compressão resistente do mesmo, acompanhada de alteração na resposta póscrítica e na ductilidade da barra. Em alguns modelos, os furos reduziram a força de flambagem local da alma, fazendo com que a maior parte da força de compressão fosse transmitida pela mesa e pelo enrijecedor, induzindo o perfil à falha pelo modo distorcional.

Para avaliar experimentalmente o comportamento de barras formadas a frio em flexão com furos na alma, Moen et al (2013) realizaram ensaios em dezoito peças, sendo nove com furos e nove sem furos. Uma seção transversal comercial sujeita à distorção foi escolhida e atenção especial foi dada para a amplificação da deformação causada pela instabilidade distorcional nas peças com furos. Cada modelo possuía três furos retangulares em sua alma. A dimensão dos furos foi escolhida de modo a garantir que a relação entre inércia líquida na região dos furos $\left(I_{\text {net }}\right)$ e inércia bruta da seção transversal $\left(\mathrm{I}_{\mathrm{g}}\right)$ fosse de 0,80 a 0,90 .

Moen et al (2013) observaram que o momento resistente sofreu uma redução média de $19 \%$ para as peças com $I_{\text {net }} / I_{g}=0,90$ e de $34 \%$ para as peças com $I_{\text {net }} / I_{g}=0,80$. Nestas peças foi observada instabilidade distorcional na região do furo, acompanhada de instabilidade local na região comprimida da alma próxima ao furo. Para alguns corpos de prova observou-se o colapso repentino da peça na região do furo. Também foi comprovado que o Método da Resistência Direta (MRD) é viável para o dimensionamento de perfis com a presença de furos.

Neste trabalho é apresentado o método da largura efetiva da norma norte americana AISI S100-16 para o dimensionamento perfis formados a frio com furos. O software desenvolvido é apresentado, com uma breve descrição de suas funcionalidades. Também foi apresentado de maneira mais detalhada o comportamento de barras comprimidas com o Ue $90 \times 40 \times 12 \times 0,80$ com furo oblongo na alma submetido à compressão centrada. Em seguida, são apresentadas as porcentagens de redução para os perfis usuais do LSF do tipo Ue com alturas da alma de $90 \mathrm{~mm}, 140 \mathrm{~mm}$ e $200 \mathrm{~mm}$. Os resultados podem ser utilizados para o projeto de barras comprimidas, com os 
perfis e condições analisadas, para prever a influência dos furos na capacidade resistente à compressão.

\section{Revisão bibliográfica: Prescrições da norma norte americana AISI S100-16}

A norma do American Iron and Steel Institute (AISI) S100-16, North American ColdFormed Steel Specifications, trata do dimensionamento de perfis formados a frio. Esta norma apresenta uma formulação completa para o dimensionamento de perfis formados a frio com a presença de furos. A nomenclatura adotada é apresentada na Figura 1.

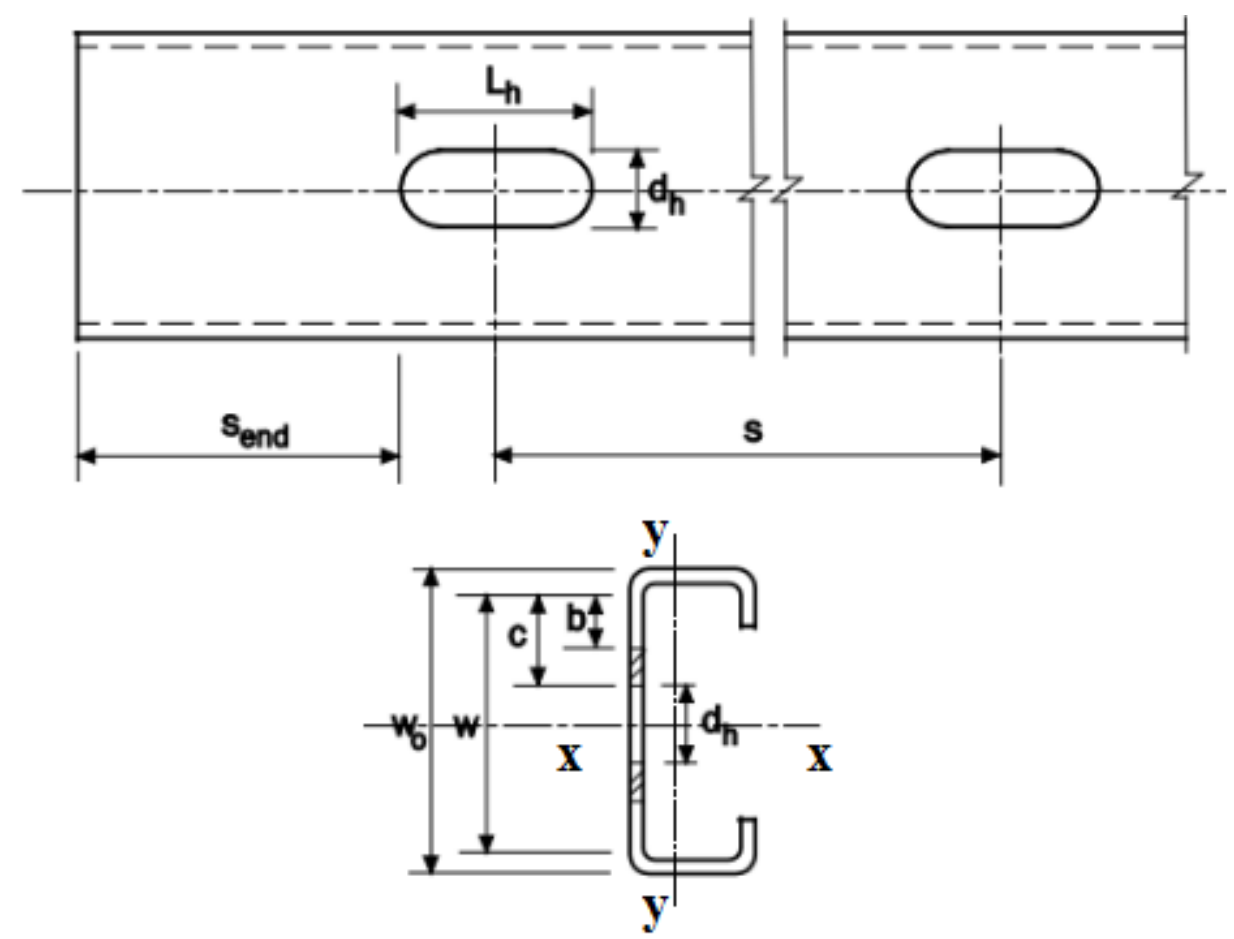

Figura 1 - Nomenclatura adotada na norma AISI S100-16 (modificada)

Na Figura 1, $L_{h}$ é o comprimento do furo, $d_{h}$ é o diâmetro do furo, Send é a distância entre borda do furo e borda do perfil, s é a distância entre centro de furos, $w_{0}$ é altura da seção transversal, w é a largura da parte plana da alma, c é a largura do elemento não enrijecido adjacente ao furo e b é a largura efetiva deste elemento.

\subsection{Estados-limites aplicáveis}

Segundo a norma AISI S100-16 barras submetidas à força axial de compressão estão sujeitas à três estados-limites, sendo estes $i$ ) escoamento e flambagem global (por 
flexão, torção ou flexo torção); ii) flambagem local interagindo com escoamento e flambagem global; e iii) flambagem distorcional. Informações adicionais sobre os estados-limites podem ser obtidas nos itens E2, E3 e E5 da norma AISI S100-16, respectivamente.

Ainda segundo a forma AISI S100-16 barras submetidas à flexão estão sujeitas à três estados-limites, sendo estes i) escoamento e flambagem lateral com torção; ii) flambagem local interagindo com escoamento e flambagem global; e iii) flambagem distorcional. Informações adicionais sobre os estados-limites podem ser obtidas nos itens F2, F3 e F5 da norma AISI S100-16, respectivamente.

\subsection{Método da Largura Efetiva aplicado a almas de perfis Ue submetidas à compressão uniforme}

A norma AISI S100-16 apresenta a formulação para cálculo da largura efetiva de elementos com furos. Para elementos enrijecidos uniformemente comprimidos com furos circulares, a norma norte americana recomenda, no item 1.1.1 de seu apêndice 1, a formulação para o cálculo da largura efetiva apresentada na Equação 1:

$b=w-d_{h x} s e \lambda \leq 0,673$

(equação 1a)

$b=w\left[1-(0.22) k \lambda-\left(0.8 d_{h}\right) / w+\left(0.085 d_{h}\right) / w \lambda\right] / \lambda_{n} s e \lambda \geqslant 0,673$ (equação $\left.1 b\right)$

Onde b é a largura efetiva do elemento, w é a largura da parte plana do elemento, t é a espessura do elemento, $d_{h}$ é o diâmetro do furo e $\lambda$ é o índice de esbeltez definido na seção 1.1 da norma AISI S100-16. Em todos os casos, deve-se adotar $b \leq \mathrm{w}-\mathrm{d}_{\mathrm{h}}$.

Para furos circulares, as seguintes disposições construtivas devem ser atendidas:

a) $0 \leq d_{h} / w \leq 0,50$;

b) $\mathrm{w} / \mathrm{t} \leq 70$;

c) Distância entre furos $\geq 0,50$ w;

d) Distância entre furos $\geq 3 d_{h}$.

Para o caso de elementos enrijecidos, uniformemente comprimidos, com furos não circulares, deve-se considerar a alma como dois elementos não enrijecidos adjacentes ao furo, de largura c. Desta forma, calculando-se a largura efetiva de cada elemento 
separadamente, adotando-se coeficiente de flambagem $k=0,43$, conforme recomentado na norma AISI S100-16 para elementos não enrijecidos submetidos à compressão uniforme. Adicionalmente, as seguintes disposições construtivas devem ser atendidas:

a) Distância entre centro de furos (s) $\geq 610 \mathrm{~mm}$ (24 in);

b) Distância entre o furo e o final da barra $\left(s_{\text {end }}\right) \geq 254 \mathrm{~mm}$ (10 in);

c) Profundidade do furo: $d_{h} \leq 63,5 \mathrm{~mm}(2,5 \mathrm{in})$;

d) Comprimento do furo: $L_{h} \leq 114 \mathrm{~mm}(4,5 \mathrm{in})$;

e) Relação $d_{h} / w_{o} \leq 0,50$.

Para cálculo da largura efetiva do elemento $\left(b_{d}\right)$, em estado-limite de serviço, deve-se adotar a formulação apresentada na seção 1.1(b) da norma AISI S100-16, assumindo que não existe furo na alma.

\subsection{Método da Largura Efetiva aplicado a almas de perfis Ue submetidas à}

\section{flexão}

Para almas de perfis Ue com a presença de furos e sujeitas à flexão, a norma norte americana AISI S100-16 recomenda, no item 1.1.3 do apêndice 1, que para as relações $d_{h} / h<0,38$ deve-se adotar as formulações apresentadas na seção 1.1(a) da norma mesma norma, para cálculo da largura efetiva do elemento, assumindo-se que não existe furo na alma. Sendo $\mathrm{h}$ a largura da parte plana da alma do perfil.

Para as relações $d_{h} / h \geq 0,38$, o cálculo da largura efetiva da alma deve ser feito conforme seção 1.2.1(a) da norma AISI S100-16, assumindo que a parte comprimida da alma consiste em um elemento não enrijecido adjacente ao furo, submetida à máxima tensão de compressão, $f_{1}$, neste caso.

Adicionalmente, as seguintes disposições construtivas devem ser atendidas:
a) Relação $d_{h} / h \leq 0,70$;
b) Relação $h / t \leq 200$;
c) Furos centralizados na meia altura da alma do perfil;
d) Distância entre furos $\geq 457 \mathrm{~mm}$ (18 in); 
e) Furos não circulares com raio de borda $\geq 2 \mathrm{t}$;

f) Furos não circulares com $d_{h} \leq 63,5 \mathrm{~mm}(2,5 \mathrm{in})$ e $L_{h} \leq 114 \mathrm{~mm}(4,5 \mathrm{in})$;

g) Diâmetro dos furos circulares $\leq 152 \mathrm{~mm}$ (6 in);

h) $\quad d_{h}>14,3 \mathrm{~mm}(9 / 16 \mathrm{in})$.

Para cálculo da largura efetiva do elemento, em estado-limite de serviço, deve-se adotar a formulação apresentada na seção 1.1.2(a) da norma AISI S100-16, assumindo que não existe furo na alma.

\subsection{Força resistente ao cisalhamento de perfis Ue com furos na alma}

O item G3 da norma AISI S100-16 recomenda que a força resistente ao cisalhamento de perfis Ue com furos na alma seja calculada conforme a seção G2.3 da mesma norma, que trata de perfis sem furos. Em seguida, deve-se aplicar o fator de redução $q_{s}$ sobre a força resistente, conforme apresentado na Equação 2:

$q_{s}=1.0$, se eft $\geq 54$

(Equação 2a)

$q_{S}=e f 54 t, g e 5 \leq e f t<54$

Onde c é um fator que varia para furos circulares e não circulares e pode ser obtido pela Equação 3:

$\varepsilon=h / 2-d_{h} / 2,38$, para furos etreulares

(Equação 3a)

$\epsilon=\hbar / 2-d_{h} / 2$, prara furos nå $\sigma$ circulares

(Equação 3b)

Adicionalmente, as disposições construtivas apresentadas anteriormente para o cálculo da largura efetiva de almas de perfis Ue submetidas à flexão devem ser atendidas.

\subsection{Método da Resistência Direta aplicado à perfis com furos}

A norma AISI S100-16 apresenta nas seções E 4.2 e F 4.2 as formulações para o dimensionamento de perfis com a presença de furos, respectivamente. Moen e Schafer (2009) apresentam uma metodologia para obtenção das cargas críticas de flambagem de perfis com furos pelo método das faixas finitas, com o auxílio do CUFSM (Cornell University Finite Strip Method), um software para análise da estabilidade elástica de perfis formados a frio, desenvolvido por Li e Schafer (2010). 


\section{Apresentação do software desenvolvido}

\subsection{Java e a Linguagem Orientada a Objetos}

Java é uma linguagem computacional de programação orientada a objetos (POO), desenvolvida nos anos 90, pela empresa Sun Microsystems e se tornou muito popular nos anos 2000, inclusive no meio acadêmico. Este tipo de linguagem trabalha diferentemente das linguagens convencionais, pois toda informação é compilada para um bytecode e executada por uma plataforma virtual.

Segundo Santos (2001), programadores que trabalham com programação orientada a objetos criam e usam objetos provenientes de classes. Estas são estruturas que contém dados para representar algum modelo e executar operações com tais dados.

Como por exemplo, no software desenvolvido, criou-se a classe U_section que armazena os dados de uma seção transversal U. Informando a esta classe os valores de altura, largura da mesa e espessura da chapa, ela é capaz de armazenar tais propriedades. No software cada tipo de seção transversal é representado por uma classe. Outra classe chamada Calculator recebe as informações provenientes daquelas que representam as seções e é capaz de calcular e armazenar suas propriedades geométricas, tais como área bruta, momentos de inércia, módulo elástico e afins.

Segundo Santos (2001), os dados de uma classe são armazenados em campos. Cada campo é composto por um tipo de dado, podendo ser um número inteiro, um boolean, um float, um double, ou até mesmo uma classe anteriormente já criada. Estas variáveis podem ser acessíveis ou não para outras classes.

As operações realizadas dentre de uma classe compõem seus métodos. Estes podem receber um ou mais argumentos para realizar cálculos. A altura, largura da mesa e espessura da chapa são os argumentos dos métodos que calculam as propriedades geométricas da seção transversal da classe U_Section, por exemplo.

\subsection{Estruturação básica do aplicativo}

A linguagem Java, permite que se agrupem classes que mantém alguma relação entre si em pacotes. Para a criação de pacotes, basta declarar a estas classes que elas pertencem a determinado pacote e criar uma organização destas classes em diretórios. 
No programa foram adotados nove pacotes, sendo eles: i) Geometria; ii) Seções; iii) Modelo; iv) Esforço Resistente; v) Verificações; vi) Biblioteca; vii) GIG e viii) Aplicativo; e ix) Útil.

O pacote Geometria armazena as classes que representam a geometria básica da seção transversal. O pacote Seções armazena uma interface que implementa as classes de diversas seções transversais existentes, existe também uma classe que faz o cálculo das propriedades geométricas do perfil que são usadas no dimensionamento.

O pacote Modelo armazena as classes relacionadas com o modelo de cálculo, nele estão as propriedades das barras, do material, os valores de carregamentos solicitantes de cálculo e afins. O pacote Esforço Resistente armazena as classes que fazem o cálculo dos esforços resistentes e outros cálculos usados durante o dimensionamento tais como os esforços críticos elásticos e as propriedades efetivas das seções.

O pacote Verificações contém as classes que verificam se os esforços resistentes são maiores que os solicitantes, fazem a verificação composta de esforços e afins. As cargas críticas de flambagem devem ser fornecidas como dado de entrada e podem ser obtidas com o auxílio do CUFSM.

O pacote Biblioteca armazena classes, onde está uma biblioteca dos principais matérias e seções transversais comerciais.

O pacote GIG é responsável pela interface gráfica do software. O pacote Aplicativo armazena a classe Aplicativo e é responsável por executar o programa. O pacote Útil armazena algumas classes predefinidas para acesso de teclado e outras funcionalidades afins.

\subsection{Apresentação da interface gráfica do programa}

Para apresentação da interface gráfica do aplicativo desenvolvido, tomou-se o exemplo de uma viga Ue $140 \times 40 \times 12 \times 0,80$, na qual foi realizado um furo oblongo de 32 $\mathrm{mm}$ por $50 \mathrm{~mm}$. A viga foi fabricada em aço ZAR230, com comprimento de $2.400 \mathrm{~mm}$ e um travamento central. Considerou-se que a viga esteja submetida a um momento fletor solicitante de cálculo $M_{s d x}=93,89 \mathrm{kN} \mathrm{cm}$. O dimensionamento é apresentado nas Figuras 2 a 5. 


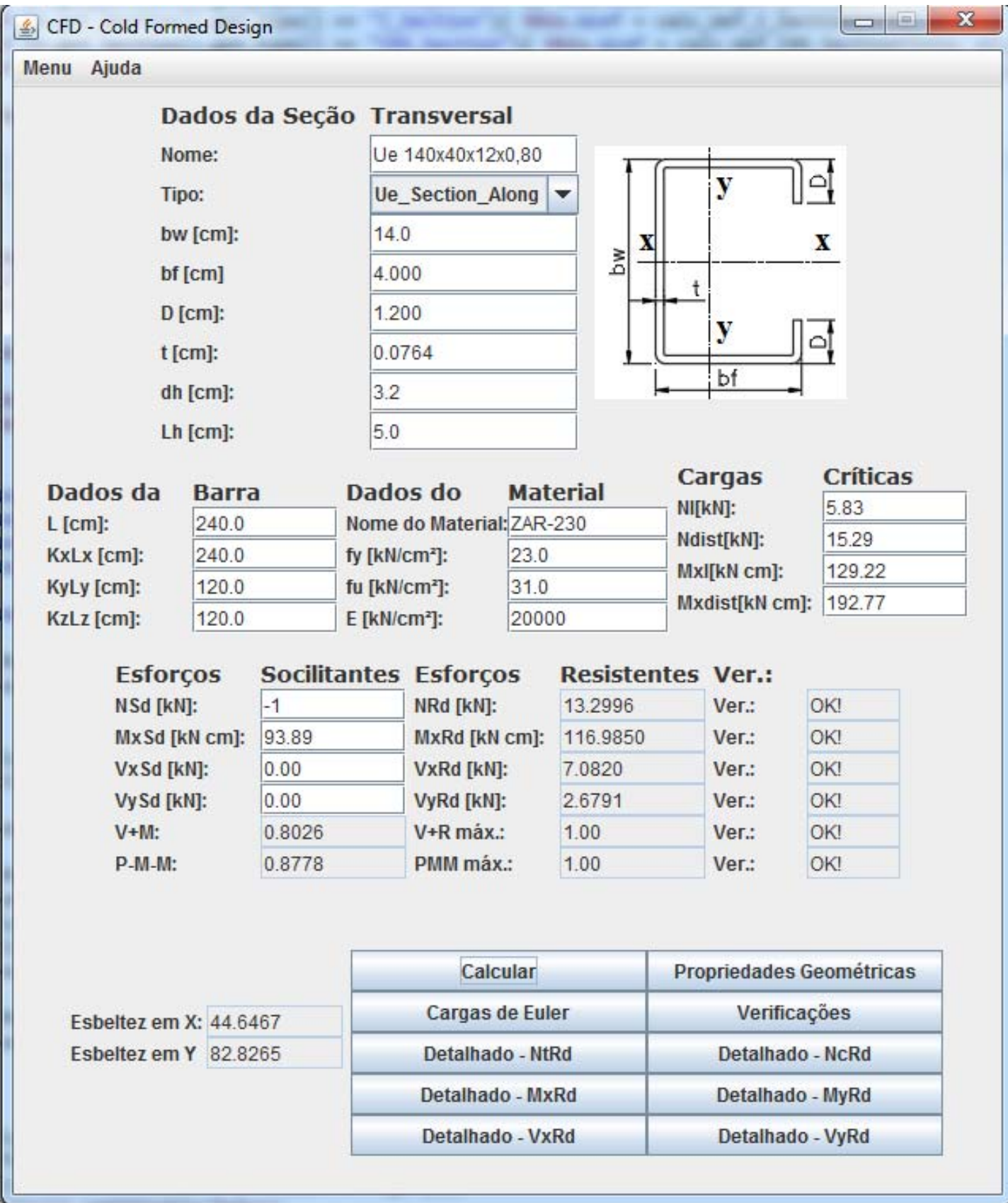

Figura 2 - Dados de Entrada

\begin{tabular}{|c|c|c|c|}
\hline Propriedades Ge & étricas & 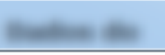 & \begin{tabular}{|l|l|l|}
$\square$ & $\square$ & $x$ \\
\end{tabular} \\
\hline \multicolumn{4}{|l|}{ Menu Ajuda } \\
\hline \multicolumn{4}{|c|}{ Propriedades Geométricas - Ue $140 \times 40 \times 12 \times 0,80$} \\
\hline \multirow{5}{*}{$\begin{array}{l}\mathrm{Ag}[\mathrm{cm} 2]: \\
\text { Cx [cm]: } \\
\text { Ix [cm4]: } \\
\text { Ixy [cm4]: } \\
\text { rx [cm]: }\end{array}$} & 1.8258 & \multirow{2}{*}{$\begin{array}{l}\mathrm{m} \text { [kg/m]: } \\
\text { Cy [cm2]: }\end{array}$} & 1.4332 \\
\hline & 1.0477 & & 7.0000 \\
\hline & 52.7585 & \multirow{2}{*}{$\begin{array}{l}\text { ly [cm4]: } \\
\text { It [cm4]: }\end{array}$} & 3.8324 \\
\hline & 0.0000 & & 0.0036 \\
\hline & 5.3755 & \multirow{4}{*}{$\begin{array}{l}\text { ry [cm]: } \\
\text { Wx_inf [cm3]: } \\
\text { Wy_dir [cm3]: } \\
\text { r0 [cm]: }\end{array}$} & 1.4488 \\
\hline Wx_sup [cm3]: & 7.5783 & & 7.5783 \\
\hline Wy_esq [cm3]: & 3.7962 & & 1.3151 \\
\hline \multirow[t]{2}{*}{ Cw [cm6]: } & 151.9526 & & 6.1911 \\
\hline & \multicolumn{2}{|c|}{ Fechar } & \\
\hline
\end{tabular}

Figura 3 - Propriedades Geométricas da Seção Transversal 


\begin{tabular}{|l|l|l|l|}
\hline Esforços Criticos Elasticos & & \\
\hline Menu Ajuda & \multicolumn{2}{|c|}{ Cargas de Euler } & \\
\cline { 1 - 2 } KxLx [cm]: & 240.0000 & KyLy [cm]: & 120.0000 \\
\hline $\begin{array}{l}\text { KzLz [cm]: } \\
\text { Ney [kN]: }\end{array}$ & 120.0000 & Nex [kN]: & 180.8005 \\
\hline $\begin{array}{l}\text { Nexz [kN]: } \\
\text { Mex [kN cm]: }\end{array}$ & 52.5339 & Nez [kN]: & 55.0551 \\
\hline & 51.1870 & Ne [kN]: & 51.1870 \\
\hline
\end{tabular}

Figura 4 - Esforços críticos elásticos

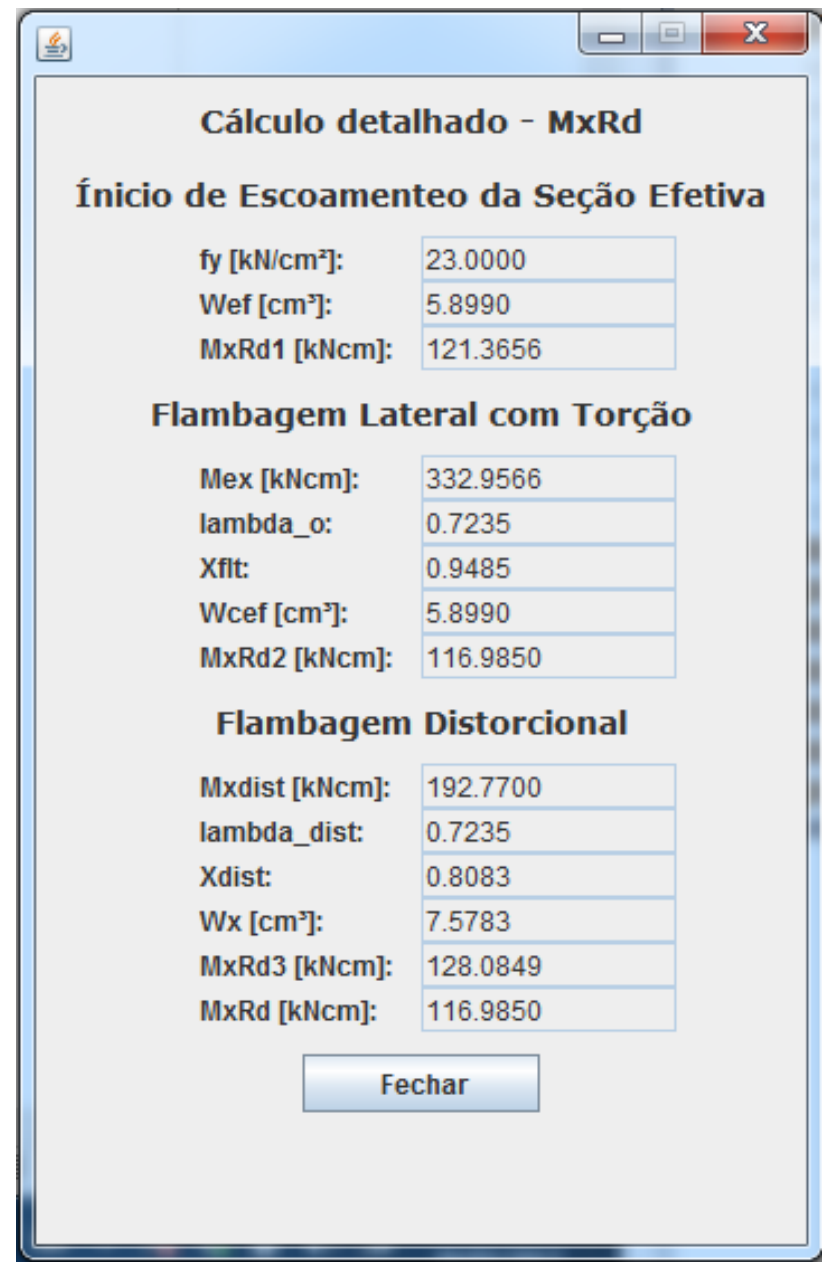

Figura 5 - Cálculo Detalhado de $M_{x R d}$ 


\section{Estudo de barras comprimidas do sistema LSF com furo oblongo}

$\mathrm{Na}$ Figura 6 tem-se o gráfico que apresenta o comportamento do perfil Ue $90 \times 40 \times 12 \times 0,80$ comprimido, com furos oblongos na alma. Este gráfico apresenta a força de compressão resistente do perfil em função de seu comprimento (limitado a $400 \mathrm{~cm}$ ) e considera a relação $d_{h} / h$ variando de 0,10 até 0,50 , além de apresentar 0 comportamento do perfil sem furos. Para elaboração do gráfico, adotou-se aço ZAR230 e considerou-se um travamento central, de modo que $K_{y} L_{y}=K_{z} L_{z}=K_{x} L_{x} / 2$. Considerou-se furos oblongos com comprimento de $110 \mathrm{~mm}$.

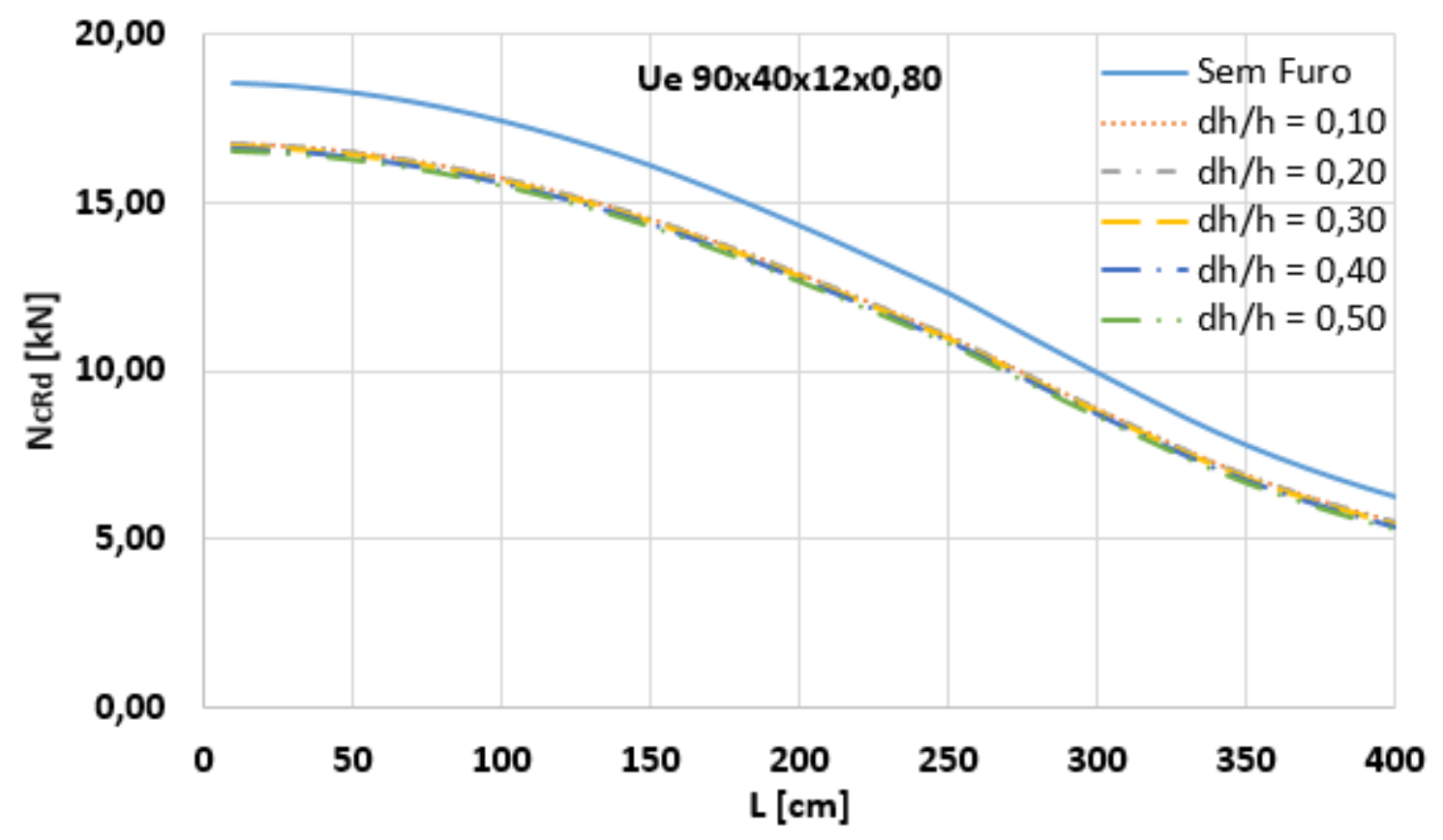

Figura 6 - Gráfico força resistente em função do comprimento do perfil Ue $90 \times 40 \times 12 \times 0,80$ com a presença de furos

As barras sujeitas à força axial de compressão, que possuem furos oblongos, apresentam redução da força axial de compressão resistente de cálculo, como pode ser observado na Figura 6 para o perfil Ue $90 \times 40 \times 12 \times 0,80$. Observou-se que para 0 perfil estudado, a redução percentual máxima (tomada como a maior redução da força axial de compressão resistente dividida pela força resistente do perfil sem furos) varia de $11,7 \%$ a $15,8 \%$.

Conforme apresentado na Tabela 1, para uma determinada barra pode-se definir a redução percentual máxima (a) para sua força axial de compressão resistente de cálculo, em função do comprimento do perfil e da relação $d_{h} / h$. 
Tabela 1 - Percentual de redução da força axial de compressão resistente para o perfil Ue $90 \times 40 \times 12 \times 0,80$ com furos

\begin{tabular}{|c|c|c|c|c|c|c|c|}
\hline $\begin{array}{l}K_{x} L_{x} \\
{[\mathrm{~cm}]}\end{array}$ & $\begin{array}{c}K_{z} L_{z}= \\
K_{y} L_{y}[\mathrm{~cm}]\end{array}$ & $\begin{array}{c}\mathbf{N}_{\text {cRd }}[\mathrm{kN}] \\
\text { (Sem Furos) }\end{array}$ & $\begin{array}{c}a \\
d_{h} / h=0,10\end{array}$ & $\stackrel{a}{d_{h} / h=0,20}$ & $\stackrel{a}{d_{h} / h=0,30}$ & $\stackrel{a}{d_{h} / h=0,40}$ & $\stackrel{a}{d_{h} / h=0,50}$ \\
\hline 20 & 10 & 18,53 & $9,7 \%$ & $9,9 \%$ & $10,2 \%$ & $10,6 \%$ & $11,1 \%$ \\
\hline 40 & 20 & 18,40 & $9,7 \%$ & $9,9 \%$ & $10,2 \%$ & $10,6 \%$ & $11,1 \%$ \\
\hline 60 & 30 & 18,17 & $9,7 \%$ & $9,9 \%$ & $10,2 \%$ & $10,6 \%$ & $11,2 \%$ \\
\hline 80 & 40 & 17,85 & $9,7 \%$ & $10,0 \%$ & $10,3 \%$ & $10,7 \%$ & $11,2 \%$ \\
\hline 100 & 50 & 17,45 & $9,8 \%$ & $10,0 \%$ & $10,3 \%$ & $10,7 \%$ & $11,2 \%$ \\
\hline 120 & 60 & 16,97 & $9,8 \%$ & $10,0 \%$ & $10,3 \%$ & $10,7 \%$ & $11,3 \%$ \\
\hline 140 & 70 & 16,42 & $9,8 \%$ & $10,1 \%$ & $10,4 \%$ & $10,8 \%$ & $11,4 \%$ \\
\hline 160 & 80 & 15,79 & $9,9 \%$ & $10,1 \%$ & $10,5 \%$ & $10,9 \%$ & $11,5 \%$ \\
\hline 180 & 90 & 15,08 & $9,9 \%$ & $10,2 \%$ & $10,5 \%$ & $11,0 \%$ & $11,7 \%$ \\
\hline 200 & 100 & 14,33 & $10,0 \%$ & $10,3 \%$ & $10,6 \%$ & $11,1 \%$ & $11,8 \%$ \\
\hline 220 & 110 & 13,55 & $10,1 \%$ & $10,4 \%$ & $10,8 \%$ & $11,3 \%$ & $12,0 \%$ \\
\hline 240 & 120 & 12,73 & $10,2 \%$ & $10,5 \%$ & $10,9 \%$ & $11,4 \%$ & $12,2 \%$ \\
\hline 260 & 130 & 11,85 & $10,3 \%$ & $10,6 \%$ & $11,1 \%$ & $11,7 \%$ & $12,5 \%$ \\
\hline 280 & 140 & 10,89 & $10,5 \%$ & $10,9 \%$ & $11,4 \%$ & $12,0 \%$ & $12,9 \%$ \\
\hline 300 & 150 & 9,95 & $10,7 \%$ & $11,1 \%$ & $11,7 \%$ & $12,4 \%$ & $13,3 \%$ \\
\hline 320 & 160 & 9,04 & $11,0 \%$ & $11,4 \%$ & $12,0 \%$ & $12,8 \%$ & $13,8 \%$ \\
\hline 340 & 170 & 8,18 & $11,2 \%$ & $11,7 \%$ & $12,3 \%$ & $13,2 \%$ & $14,4 \%$ \\
\hline 360 & 180 & 7,44 & $11,4 \%$ & $11,9 \%$ & $12,6 \%$ & $13,6 \%$ & $14,9 \%$ \\
\hline 380 & 190 & 6,81 & $11,5 \%$ & $12,1 \%$ & $12,9 \%$ & $13,9 \%$ & $15,4 \%$ \\
\hline 400 & 200 & 6,26 & $11,7 \%$ & $12,3 \%$ & $13,2 \%$ & $14,3 \%$ & $15,8 \%$ \\
\hline \multicolumn{3}{|c|}{ Redução média } & $10,3 \%$ & $10,6 \%$ & $11,1 \%$ & $11,7 \%$ & $12,5 \%$ \\
\hline \multicolumn{3}{|c|}{ Redução máxima } & $11,7 \%$ & $12,3 \%$ & $13,2 \%$ & $14,3 \%$ & $15,8 \%$ \\
\hline \multicolumn{3}{|c|}{ Redução mínima } & $9,71 \%$ & $9,92 \%$ & $10,21 \%$ & $10,58 \%$ & $11,11 \%$ \\
\hline
\end{tabular}


A Figura 7 apresenta o gráfico com as reduções percentuais da força axial de compressão resistente do perfil Ue $90 \times 40 \times 12 \times 0,80$, com relação $d_{h} / h$ variando de 0,10 a 0,50, em função do comprimento do perfil variando de 0 até $400 \mathrm{~cm}$.

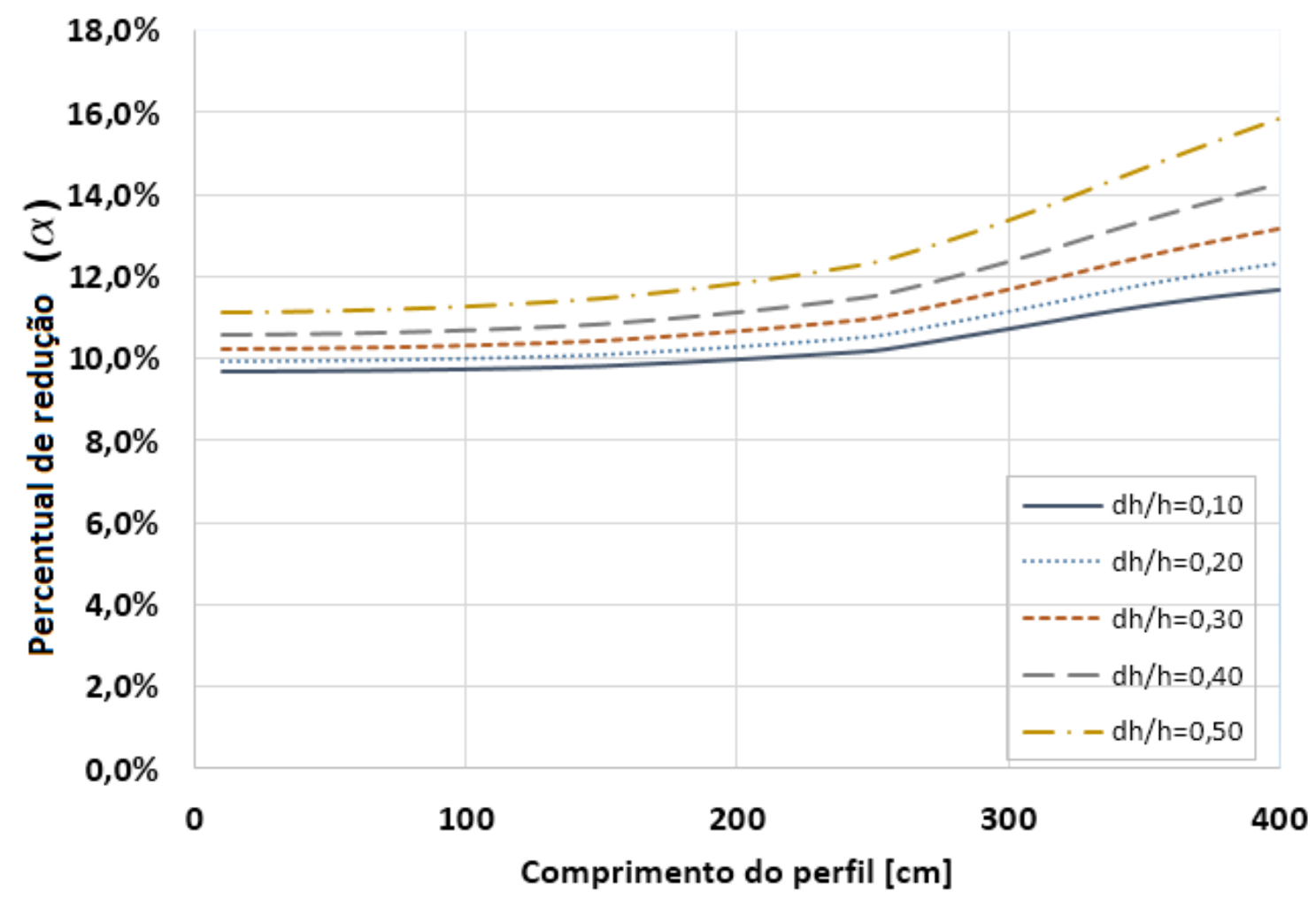

Figura 7 - Porcentagem de redução da força axial de compressão resistente para relações $\mathrm{dh} / \mathrm{h}$ variando de 0,10 até 0,50 em função do comprimento do perfil Ue $90 \times 40 \times 12 \times 0,80$ com furos

É possível observar na Figura 7, que o percentual de redução a aumenta com o aumento do comprimento do perfil. Observa-se também que redução percentual a aumenta conforme a relação $d_{h} / h$ cresce.

A Figura 8 apresenta a variação da redução percentual a em função da relação $d_{h} / h$, para os comprimentos do perfil variando de $50 \mathrm{~cm}$ até $400 \mathrm{~cm}$. 


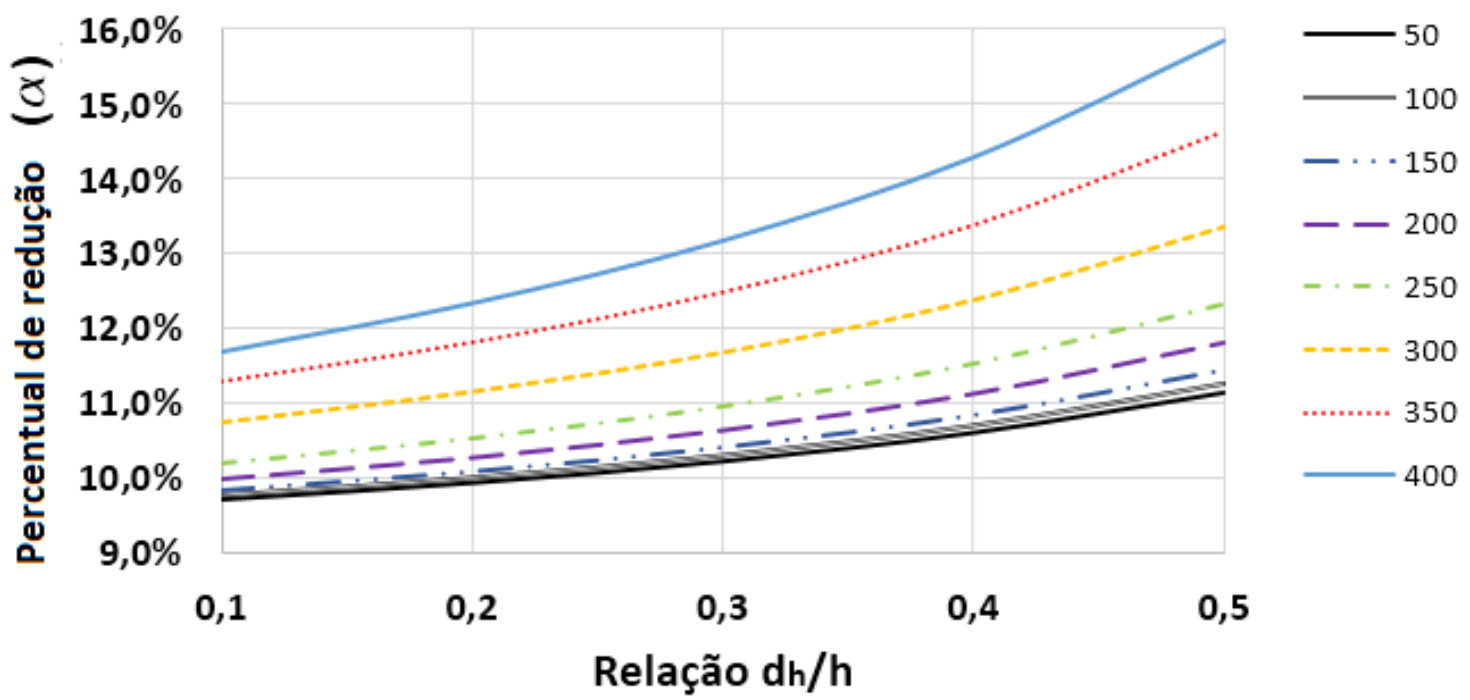

Figura 8 - Variação da redução percentual a em função da relação $d_{h} / h$, para os comprimentos do perfil Ue $90 \times 40 \times 12 \times 0,80$ variando de $50 \mathrm{~cm}$ até $400 \mathrm{~cm}$

A Tabela 2 estende o cálculo da redução percentual da força axial de compressão resistente para os demais perfis usualmente adotados no sistema LSF, apresentando a maior redução percentual a para perfil com comprimento de até $400 \mathrm{~cm}$ (com $K_{y} L_{y}=K_{z} L_{z}=K_{x} L_{x} / 2$ ) e relação $d_{h} / h$ variando de 0,10 até 0,50.

Tabela 2 - Porcentagem máxima de redução da força axial de compressão resistente para perfis usualmente adotados no sistema LSF

\begin{tabular}{|c|c|c|c|c|c|}
\hline Perfil & $\stackrel{a}{d h / h=0,10}$ & $\stackrel{a}{d h / h=0,20}$ & $\begin{array}{c}a \\
d h / h=0,30\end{array}$ & $\stackrel{a}{d h / h=0,40}$ & $\stackrel{a}{d h / h=0,50}$ \\
\hline Ue $90 \times 40 \times 12 \times 0,80$ & $11,68 \%$ & $12,33 \%$ & $13,17 \%$ & $14,28 \%$ & $15,83 \%$ \\
\hline Ue $90 \times 40 \times 12 \times 0,95$ & $12,00 \%$ & $12,89 \%$ & $14,03 \%$ & $15,55 \%$ & $18,16 \%$ \\
\hline Ue $90 \times 40 \times 12 \times 1,25$ & $12,01 \%$ & $13,20 \%$ & $14,93 \%$ & $18,71 \%$ & $23,38 \%$ \\
\hline Ue $140 \times 40 \times 12 \times 0,80$ & $12,04 \%$ & $12,31 \%$ & $12,66 \%$ & $13,14 \%$ & $13,53 \%$ \\
\hline Ue $140 \times 40 \times 12 \times 0,95$ & $13,06 \%$ & $13,43 \%$ & $13,92 \%$ & $14,57 \%$ & $15,10 \%$ \\
\hline Ue $140 \times 40 \times 12 \times 1,25$ & $14,44 \%$ & $15,07 \%$ & $15,88 \%$ & $16,97 \%$ & $17,87 \%$ \\
\hline Ue $200 \times 40 \times 12 \times 0,80$ & $13,00 \%$ & $13,21 \%$ & $13,55 \%$ & - & - \\
\hline Ue $200 \times 40 \times 12 \times 0,95$ & $14,20 \%$ & $14,49 \%$ & $14,95 \%$ & - & - \\
\hline Ue $200 \times 40 \times 12 \times 1,25$ & $15,95 \%$ & $16,42 \%$ & $17,18 \%$ & - & - \\
\hline
\end{tabular}


Quando furos oblongos são realizados na alma de um perfil submetido à compressão centrada, esta deixa de ser tratada como um elemento vinculado-vinculado com coeficiente de flambagem k=4 (Figura 9-a), e passa a ser considerada como dois elementos vinculado-livre não enrijecidos, adjacentes ao furo, ambos com $k=0,43$ (Figura 9-b). A largura efetiva de cada elemento deve ser calculada separadamente e resulta em um valor menor do que no elemento vinculado-vinculado e consequentemente em uma menor área efetiva. A variação da condição de contorno da alma pode provocar grande redução da força axial de compressão resistente do perfil, conforme pode ser constatado na Tabela 2.

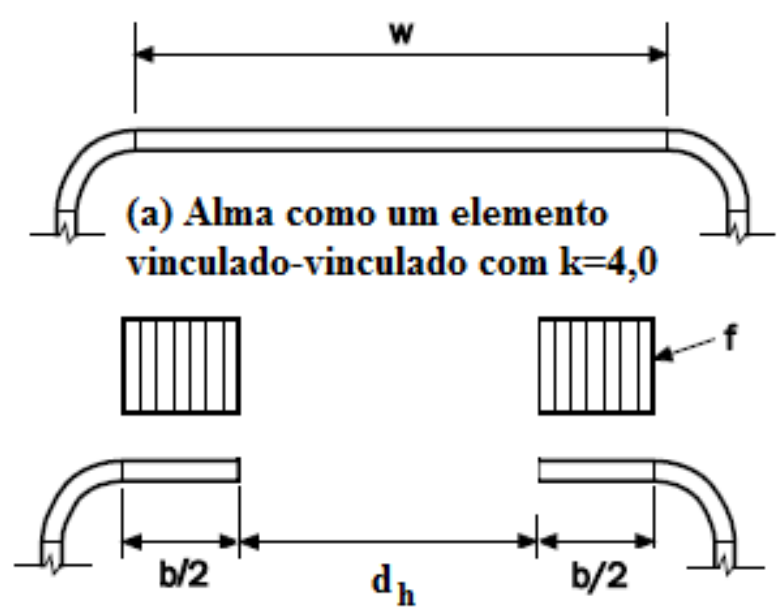

(b) Alma como dors elemento vinculado-livre com $\mathrm{k}=0, \mathbf{4 3}$

Figura 9 - Variação da condição de contorno da alma. (a) elemento vinculadovinculado; (b) elemento vinculado-livre

Observou-se que a redução percentual a cresce com o aumento da relação $d_{h} / h$, o que é esperado, uma vez que o aumento no diâmetro do furo reduz a largura dos elementos adjacentes ao mesmo, resultando em menor área efetiva.

Observou-se também que redução percentual da força resistente cresce com o aumento do comprimento do perfil. O aumento do comprimento da barra resulta em um aumento de esbeltez, o que favorece a flambagem global da barra, reduzindo a tensão aplicada no cálculo das larguras efetivas, desfavorecendo a flambagem local. Desta maneira o diâmetro do furo tem sua importância aumentada, pois uma maior relação $d_{h} / h$ implica na redução da área liquida, como pode ser observado na Figura 8. 
Os resultados da Tabela 2 podem ser utilizados para o projeto de barras comprimidas, com os perfis e condições analisadas, para prever a influência dos furos na capacidade resistente à compressão.

\section{Conclusões}

Conforme comentado neste trabalho, os perfis formados a frio, adotados no sistema Light Steel Framing, usualmente recebem furos para passagem e acomodação de tubulações elétricas, hidráulicas e outros. A presença dos furos reduz a força resistente dos perfis. Entretanto, as normas brasileiras que tratam do dimensionamento de perfis formados a frio somente contemplam em seu escopo a existência de furos nos capítulos de barras submetidas à força axial de tração e de ligações parafusadas. Deste modo, o engenheiro que se depara com tal situação, pode fazer uso da norma norte americana AISI S100-16. Essa norma apresenta formulação para o cálculo da largura efetiva de elementos uniformemente comprimidos e de elementos submetidos à flexão com a presença de furos.

A norma AISI S100-16 apresenta métodos para o cálculo da força resistente ao cisalhamento e da força resistente a web crippling de perfis com a presença de furos. Para estes casos, deve-se calcular a força resistente considerando que não existem furos nos perfis, e em seguida aplica-se um fator de redução sobre esta força. A norma AISI S100-16 apresenta também uma adaptação do método da resistência direta para o dimensionamento de vigas e pilares com a presença de furos.

O software desenvolvido, e apresentado neste trabalho, está apto para o dimensionamento de perfis com a presença de furos, incluindo, inclusive, os estadoslimites distorcionais. Informações adicionais sobre o cálculo das forças axiais e momentos fletores de flambagem elástica de perfis com furos, necessários para o dimensionamento, podem ser obtidas na AISI S100-16.

Observou-se que quando furos oblongos são realizados na alma de um perfil submetido à compressão, esta deixa de ser tratada como um elemento vinculadovinculado com coeficiente de flambagem $k=4$, e passa a ser considerada como dois elementos vinculado-livre não enrijecidos adjacentes ao furo, ambos com $k=0,43$. A 
largura efetiva de cada elemento deve ser calculada separadamente e resulta em um valor menor do que no elemento vinculado-vinculado.

Ressalta-se as observações de Moen e Schafer (2009) sobre a redução da rigidez rotacional fornecida pela alma à mesa, quando furos são feitos na alma de perfis formados a frio, de modo que força a axial de flambagem distorcional elástica e momento fletor de flambagem distorcional elástica diminuem. Observa-se também resultados condizentes com os estudos de Moen e Schafer (2008), onde estes concluíram que a presença de furos oblongos discretos na alma de perfis Ue sujeitos à força axial de compressão provoca uma redução na força axial de compressão resistente do mesmo, acompanhada da alteração da resposta pós-crítica e na ductilidade da barra.

Sugere-se, para trabalhos futuros, a elaboração de gráficos de pré-dimensionamento de barras em compressão com a presença de furos, conforme o que foi apresentado na Figura 6 para todos os perfis usualmente aplicados no sistema LSF. Recomenda-se também a elaboração de gráficos de pré-dimensionamento para barras em flexão e barras em flexo-compressão com a presença de furos, conforme apresentados por Caldas et al (2015a, 2015b). Tais gráficos poderão ser utilizados por engenheiros e arquitetos no processo de concepção estrutural e dimensionamento.

\section{Agradecimentos}

Os autores deste trabalho agradecem aos órgãos de fomento à pesquisa brasileiros CNPq, CAPES e FAPEMIG e ao Centro Brasileiro de Construção em Aço - CBCA.

\section{Referências bibliográficas}

ABNT NBR 14762:2010. Dimensionamento de estruturas de aço constituídas por perfis formados a frio. Associação Brasileira de Normas Técnicas, Rio de Janeiro, 2010.

AISI S100-16. North American Specification for the Design of Cold-Formed Steel Structural Members. American Iron and Steel Institute, Washington, 2016. 
CALDAS, Rodrigo Barreto; RODRIGUES, Francisco Carlos; MEIRA, Lucimar de Oliveira. Prédimensionamento de perfis de aço para o sistema light steel Framing - exemplo. Revista da Estrutura de Aço, CBCA, 2015a.

CALDAS, Rodrigo Barreto; RODRIGUES, Francisco Carlos; MEIRA, Lucimar de Oliveira. Prédimensionamento de perfis de aço para o sistema light steel Framing - gráficos. Revista da Estrutura de Aço, CBCA, 2015b.

Li, Z., \& Schafer, B. W., 2010a. Buckling analysis of cold-formed steel members with general boundary conditions using CUFSM: conventional and constrained finite strip methods.

Proceedings of the $\mathbf{2 0}^{\text {th }}$ Int, I. Spec. Conf. on Cold-Formed Steel Structures. St. Louis, MO. 2010

LUE, D. M; Liu, J. LIN, C. H. Numerical Evaluation on Warping Constants of General ColdFormed Steel Open Sections. Steel Structures 7, 297-309. 2007

MOEN, C. D.; \& SCHAFER, B. W. Experiments on cold-formed steel columns with holes. ThinWalled Structures, v 46, p. 1164-1182. 2008.

MOEN, C. D.; \& SCHAFER, B. W. Elastic Buckling of cold-formed steel columns and beams with holes. Journal of Structural Engineering. v 47. , p. 2812-2824, 2009.

MOEN, C. D., SCHUDLICH, A. \&HEYDEN, A. Experiments on Cold-Formed Steel C-Section Joists with Unstiffened Web Hole. Journal of Structural Engineering.139 (5) pp. 695-704. 2013.

RODRIGUES, Francisco Carlos; CALDAS, Rodrigo Barreto. Steel Framing: Engenharia. Série Manual de Construção em Aço, IBS/CBCA, Rio de Janeiro, 2016.

SANTOS, Rafael. Introdução à Programação Orientada a Objetos. Rio de Janeiro: Elsevier, 2010. 366 p. 